José Luis Iturrioz Leza, Universidad de Guadalajara

\title{
Análisis contrastivo. La dialéctica de la igualdad y la diferencia
}

\section{Resumen}

El método contrastivo compara dos o más elementos, categorías o estructuras dentro de una misma lengua o interlingüísticamente, identificando similitudes y diferencias para establecer relaciones de complementariedad como base para su integración en esquemas más abarcadores y abstractos que den cuenta de la constancia funcional en la variación estructural. La historia de la linguiística se ha caracterizado hasta la actualidad por utilizar un modelo descriptivo basado en una lengua particular para describir estructuras de otras lenguas. Lo mismo ha ocurrido en los dominios ontogenético y pedagógico. El método contrastivo contribuye a sentar las bases para una descripción descentrada que concilia la variación estructural con la constancia funcional. Los resultados del análisis contrastivo son la base de la tipología, y en el nivel universalístico se integra la variación tipológica en esquemas más generales llamados operaciones. Los cuatro niveles descriptivos interactúan de manera circular siguiendo dos principios, uno inductivo y otro deductivo, formando un programa integrado.

Palabras clave. Contrastivo, variación, descentramiento, continuo, géneros, clases nominales, operaciones, artículo, cláusulas relativas.

\begin{abstract}
The contrastive method compares two or more elements, categories or structures within the same language or interlinguistically, identifying similarities and differences to establish complementarity relationships as a basis for their integration into more comprehensive and abstract schemes that account for the functional constancy in the structural variation. In the history of linguistics a model based on a particular language has often been used to describe the structure of other languages. The same has happened in the ontogenetic and pedagogical domains. The contrastive analysis helps to lay the foundations for an off-centered description that reconciles structural variation with functional constancy. The results of the contrastive analysis must be the basis of typology, and at the universalistic level typological variation
\end{abstract}


must be integrated into more general schemes called operations. The four descriptive levels interact in a inductive deductive circle, forming an integrated program.

Key words. Contrastive, variation, continuum, genders, noun classes, articles, relative lauses, operations. 


\section{Introducción}

Wixárika (huichol), náhuatl y en general todas lenguas indígenas mexicanas han convivido con el castellano en las escuelas del sistema supuestamente bilingüe y bicultural, ahora intercultural, diseñado para las comunidades indígenas de México, en condiciones de extrema desigualdad, con graves consecuencias para la enseñanza de las lenguas originarias. La discriminación se manifiesta en un gradual alejamiento de la cultura tradicional, en la distribución de los espacios comunicativos, en la formación de los maestros, en la elaboración de recursos didácticos, en la calendarización de las actividades escolares, y sobre todo también en el plano más abstracto de la reflexión metalingüística, mediada por el castellano. El castellano ha sido para las lenguas indoamericanas un obstáculo similar al latín para el castellano y las otras lenguas románicas, para el resto de las lenguas europeas, y a través de estas para muchas otras lenguas del mundo. Este tipo de dependencia no favorece el desarrollo de gramáticas particulares aptas para la reflexión metalingüística en cada lengua, sino que lo entorpece y hasta lo paraliza. El asunto es de relevancia cognitiva, lingüística y pedagógica.

Es natural que tratemos de entender las experiencias nuevas desde esquemas desarrollados previamente y, en especial, que tratemos de entender otra lengua desde las categorías de la propia. Esta es la invariante funcional asimilativa de toda conducta adaptativa, que debe ser compensada con la función acomodativa, que modifica y diversifica los esquemas para ajustarlos a las nuevas experiencias. ${ }^{1}$ Pasada la edad crucial para la adquisición espontánea de la lengua materna, empezamos a aprender una segunda lengua en la escuela o en la calle a través de la propia. Los hispanohablantes se acercan al wixárika a partir del castellano, proyectando las categorías del castellano sobre el wixárika. En el plano de la descripción y explicación de los fenómenos linguísticos ocurre algo similar. Los maestros wixáritaari solo pueden reflexionar sobre su lengua materna desde los conocimientos gramaticales que les han transmitido en cursos impartidos en y sobre castellano personas que no están capacitadas para reflexionar sobre ninguna de las dos lenguas. En 1978, un maestro mestizo de Tepic (Miguel Palafox Vargas), que permaneció un período largo en la Sierra Huichola, seguramente después de haber estudiado en un

1 Estoy haciendo referencia a la epistemología genética desarrollada por Piaget y expuesta en numerosos trabajos, por ejemplo, en Piaget (1971a) y Piaget (1971b). 
seminario, publicó un folleto titulado La llave del huichol, donde trata de describir esta lengua desde los paradigmas del latín, declinando los nombres según las categorías de género, número y caso, cuando esta lengua no tiene géneros ni casos y el número gramatical es un fenómeno mucho más complejo que en castellano. La primera gramática del castellano, publicada por Antonio de Nebrija en 1492, es todavía en buena medida una gramática del latín, que impide percibir las características nuevas del castellano y obliga a ver en él propiedades que ya no tiene. Por ejemplo, se habla de la declinación de los nombres y de los tres géneros del pronombre relativo que. Con ayuda de esta gramática los misioneros acometieron la empresa de describir las lenguas americanas.

Las lenguas han sido descritas en la mayoría de los casos desde otra lengua, el latín desde el griego, las lenguas europeas desde el latín a partir de finales del siglo XV y las lenguas americanas a partir del XVI.

\section{Las gramáticas coloniales}

Si lenguas tan cercanas genética, histórica y culturalmente como el latín y el castellano presentan diferencias tan grandes, ¿qué ocurre con lenguas tan distantes desde estos tres puntos de vista como las americanas? A veces los autores de las gramáticas coloniales menos ortodoxos, menos apegados a los dogmas de la tradición filosófica, percibieron con claridad que no podían encontrar equivalencias aceptables para las categorías del castellano en las lenguas del continente americano, y tuvieron que desarrollar innovaciones descriptivas.

La pregunta central de la que parten las gramáticas coloniales es cuántas partes de la oración (clases de palabras) existen en una lengua dada. En las gramáticas coloniales se percibe a veces la insatisfacción que les produce a los autores tener que describir una lengua americana con los términos tomados del modelo grecolatino. Una de las gramáticas coloniales describe la variante del náhuatl que se hablaba en el siglo XVIII en la Huasteca Potosina; el autor es el clérigo Carlos de Tapia Zenteno (1753), el padre Tapia, quien en 1721 se graduó con ella como bachiller en filosofía. La descripción gramatical consta solo de 50 páginas, pero contiene observaciones lúcidas. Tapia reconoce solamente cuatro partes de la oración y expone en el capítulo II sus argumentos para no admitir ninguna otra. Estas son el nombre, el pronombre, el verbo y el adverbio; pero al adverbio apenas le dedica una página, alegando que la clase es muy numerosa y no muestra perfiles gramaticales claros, por lo que 
aconseja limitarse a especificar su significado en el vocabulario. No reconoce una clase mayor especial de adjetivos, a diferencia del latín y del castellano, aunque llama adjetivos a los cuantificadores miec y zanachi "mucho-s”. El capítulo III, dedicado al nombre, comienza oponiéndose a todos los autores anteriores con las siguientes palabras:

\begin{abstract}
Si nombre es el que se declina por casos y no significa tiempo, podemos decir que en este idioma no hai nombre, porque ninguno se declina por casos, pues todos son indeclinables. Pero confesando que aquella es descripción gramatical del nombre latino, y no filosófica definición de su esencia, diremos que nombre [...] es aquella voz con que conocemos las cosas: y que tenga casos o no los tenga es atributo o accidente que no le pone ni le quita cosa a su naturaleza (Tapia Zenteno 1753: 8-9)
\end{abstract}

A continuación, afirma que no existen razones para postular que los nombres en el idioma mexicano (náhuatl) tienen cinco, cuatro o tres declinaciones, como hacen otros autores y reduce al absurdo la postura del padre Ávila, quien admitiendo que son cinco declinaciones, como en latín, cuando se pone a explicarlas llega a la conclusión: “cada nombre puede ser de las cinco declinaciones, y cada declinación de cada nombre”. (Tapia Zenteno 1753: 9) Su conclusión es la siguiente: "si esto pudieran decir los gramáticos latinos, no nos hubieran obligado a deletrear cinco declinaciones". (Tapia Zenteno 1753: 9) Los nombres tienen en latín diversas terminaciones para expresar los casos, lo que da pie para establecer las cinco declinaciones o clases flexivas, pero esto no ocurre en el idioma mexicano. Es el mismo argumento que utilizamos más abajo en contra de que que tenga en castellano tres géneros.

\title{
3. La gramática particular y el método distribucional
}

Por reacción a esta manera de proceder se ha reclamado que cada lengua debe ser descrita desde sus propias categorías, que el mejor método para la descripción de gramáticas particulares es el análisis distribucional, porque solo este puede garantizar la descripción de una lengua en sus propios términos. Se argumenta que la utilización de categorías obtenidas del análisis de otra lengua prefiguran la construcción que se quiere describir. La descripción de las construcciones de una lengua solo puede ser adecuada si se trabaja con categorías léxicas y morfosintácticas obtenidas en el análisis mismo de esas construcciones. La consecuencia es que las descripciones distribucionales resultan incomparables. 
Es difícil determinar qué ha sido más pernicioso para el desarrollo de la lingüística, si los intentos de describir una lengua B mediante la aplicación mecánica de categorías rígidas, preestablecidas en la descripción de una lengua A, o los intentos de reflexionar sobre una lengua desarrollando conceptos nuevos, no contaminados, que den cuenta de la estructura irrepetible e intransferible de la lengua B. Si el primer procedimiento nos hace ciegos para las diferencias, el segundo nos lleva a ver las lenguas como sistemas absolutos, inconmensurables. En realidad se trata de dos formas opuestas de glotocentrismo que impiden una comparación provechosa de las lenguas. Solo podemos lograr un conocimiento descentrado en la medida en que conseguimos modificar, diversificar y coordinar nuestros esquemas mentales para dar cabida a la diversidad dentro de la igualdad y a la unidad dentro de la diversidad.

Comparto básicamente la crítica de Croft al oportunismo metodológico, consistente en la transferencia engañosa de categorías y estructuras de una lengua a otra. Categorías y estructuras son específicas de cada lengua. Cuando solo se valoran las similitudes, se corre el peligro de establecer la identidad sobre la base de la similitud. Muchas descripciones parecen atenerse a un principio tácito como "dos cosas se parecen, luego son iguales", del que se deriva lo que Chafe (1970: 86 sig.) llamaba “el síndrome X es en realidad Y”. Tanto la historia de la gramática generativa como la de la tipología clásica están llenas de este tipo de ejercicios. Ahora bien, si atenerse exclusivamente al principio de similitud conduce a equiparaciones precipitadas, acentuar, por el contrario, el principio de diversidad lleva a hacer incomparables, inconmensurables las lenguas y las estructuras dentro de una misma lengua. Grimes (1964) se debate entre declarar dos afijos como el mismo o como dos no relacionados según el peso que conceda a las similitudes o a las diferencias.

Se requiere una vía intermedia entre la descripción de una lengua con las categorías de otra y la descripción de una lengua en sus propios términos, intransferibles. Las diferencias categoriales entre lenguas pueden ser graduales, de modo que describir una lengua no implica renunciar a todos los conceptos categoriales desarrollados previamente en la descripción de otras. Lo erróneo es describir una lengua asumiendo las categorías básicas sin ajustes. En términos extensionales, la categoría 'nombre' puede coincidir en las lenguas A y B en una parte nuclear de su composición, aún cuando en los márgenes se produzcan desfases notables. 
Se puede establecer la categoría 'nombre' para español y para huichol, constatando al mismo tiempo que algunas palabras que en español se ajustan a las propiedades morfosintácticas y distribucionales del nombre, en huichol tienen algunas propiedades verbales. Pero se requiere de un marco teórico no tan básico para explicar estas discrepancias. El éxito de la transferencia depende crucialmente de la concepción de las categorías, que no tienen que ser compactas, homogéneas, sin estructura interna.

Es incontestable que una lengua puede tener muchas categorías que son ajenas a otras; sería difícil hallar en lenguas europeas un correlato para lo que en la gramática del wixárika llamamos "ampliador de dominios funcionales", un morfema que hace posible abrir una categoría léxica a dominios funcionales que en principio le están vedados, haciendo posible que una palabra plenamente nominal en función predicativa pueda llevar morfemas de tiempo (ver más abajo). No todas las lenguas conocen la categoría 'adjetivo', por ejemplo, wixárika, lo que tiene numerosas implicaciones tanto para la estructura de estas lenguas como para la comparación tipológica.

Por el análisis estrictamente distribucional se obtienen categorías específicas de una gramática particular que son incomparables con las de otra gramática particular si no se asume una serie de conceptos básicos ordenados en un marco teórico, imprescindible incluso para impartir un curso de iniciación al trabajo de campo. Las categorías, propiedades morfosintácticas y construcciones que una gramática descriptiva obtiene en primera instancia de un análisis distribucional, no se pueden transferir a la descripción, enseñanza o aprendizaje de otra lengua, porque no pueden coincidir con las categorías que estableceríamos en aquella lengua mediante el análisis distribucional. El método distribucional ni siquiera puede garantizar por sí mismo una descripción adecuada de una gramática particular. En Iturrioz \& López (2006) describimos en detalle unas 100 deficiencias graves de la descripción de una lengua en términos distribucionales.

Si se concede el mismo peso a los principios de similitud y de diversidad, se evitan las deformaciones que emanan de tales simplificaciones. Se requiere de un método que haga a las lenguas, sus categorías y estructuras comparables, orientado a detectar tanto las diferencias como las similitudes. Las teorías lingüísticas y métodos descriptivos no basados 
en estos dos principios no pueden ser adecuados ni siquiera para la lengua en la que se originan, mucho menos se pueden transferir a otras lenguas.

\section{La dialéctica de la igualdad, la diferencia y la complementariedad}

Una de las deficiencias que Coseriu (1970:9) detecta en la gramática contrastiva de su época es su carácter marcadamente práctico

Está orientada al aprendizaje de lenguas extranjeras, a saber a partir de la lengua materna. (Coseriu 1970: 9)

Establece contrastes entre lenguas a partir de la observación de que la lengua meta presenta algo no esperado, es decir no coincidente con la lengua de partida. En la comparación se utiliza como tertium comparationis, tanto en la enseñanza como en la práctica de la traducción, una noción intuitiva y vaga de que ambas expresiones dicen lo mismo o expresan las mismas ideas. Enumera una larga serie de deficiencias para cuya solución lleva a cabo numerosas precisiones conceptuales y terminológicas, de las que deriva un programa de trabajo que denomina "gramática descriptiva comparativa” (Coseriu 1970: 29).

Las lenguas como las culturas siempre son comparables, pero nunca son iguales. Ni las lenguas ni las culturas son absolutamente diferentes, y la comparación debe orientarse a encontrar tanto las similitudes como las diferencias, lo que finalmente conduce a una relación de complementariedad. Por muy diferentes que parezcan algunas estructuras, se pueden subsumir dentro de una técnica (concepto de relevancia tipológica), por ejemplo diferentes estrategias y procedimientos para construir cláusulas determinativas como una técnica de la operación (universal) de DETERMINACIÓN junto con diferentes categorías de adjetivos y los determinantes fuertes o deícticos; por más diferentes que puedan parecer los géneros, las clases nominales y los clasificadores nominales, se pueden enmarcar en una operación (universal) que llamamos INDIVIDUACIÓN. En cada nivel, la relación es de complementariedad. La descripción como la enseñanza deben estar guiadas por dos principios complementarios, el principio de similitud y el principio de divergencia, que se subsumen en una relación de complementariedad. Si la similitud nos permite comparar y transferir categorías descriptivas en una y otra dirección y las divergencias nos impiden una 
identificación total, la complementariedad nos lleva a verlas como realizaciones alternativas de un mismo esquema abstracto o plan operativo general. Si es posible una teoría general aplicable a diversas lenguas sin proyectar indiscriminadamente la estructura de una sobre las demás, igualmente debe ser posible elaborar una propuesta didáctica general que no consista en transferir sin adaptaciones las reglas de una lengua a la otra.

La contrastación es uno de los mecanismos cognitivos más básicos que hacen posible establecer oposiciones, y las oposiciones son los datos primarios en todos los niveles del conocimiento, desde la percepción. Para que el estudio contrastivo pueda ser eficaz hay que aceptar que las lenguas o estructuras particulares pueden ser parecidas en unos aspectos, pero complementarias en otros y por lo tanto irreductibles.

En primer lugar hay que romper con la observación desde una perspectiva única. Al mismo tiempo que tratamos de comprender una lengua $\mathrm{B}$ desde la lengua $\mathrm{A}$, es imprescindible tratar de comprender la lengua A desde la lengua B. Distorsiones que produce la descripción de una lengua desde las categorías de otra, se pueden empezar a contrarrestar invirtiendo la perspectiva. Las dos perspectivas se deben integrar de manera que la comparación genere una visión tanto de las similitudes como de las diferencias en una relación de complementariedad. Nuestra lengua, que antes nos parecía natural y acorde con las categorías “objetivas” de la realidad o de la razón, nos parecerá en algunos aspectos extraña, y la otra lengua cada vez más natural. El método contrastivo es un camino de ida y vuelta, un círculo creativo.

En el desarrollo de la ciencia lingüística ha ocurrido con frecuencia que avances logrados en la descripción de una lengua extraña han servido de rebote para mejorar la descripción de la lengua del observador. Esto ocurrió con las llamadas estructuras depictivas o predicaciones secundarias que, descritas en una lengua particular, pudieron ser aplicadas después a fenómenos de otras lenguas, como los gerundios en castellano, y estructuras con los exponentes globales -ti/-me en wixárika (Iturrioz / Gómez 2006). Es obvio que el gerundio como tal no podría reencontrarse en otras lenguas, pero el concepto de predicación secundaria puede dar cabida a numerosas construcciones en diversas lenguas, aunque sean diferentes en términos morfosintácticos. El descubrimiento de que hay lenguas donde el objeto primario corresponde al receptor (Dryer 1986), codificado como objeto indirecto en 
otras lenguas, llevó a describir de manera más cabal ese fenómeno en lenguas como el latín, el inglés, el náhuatl o el wixárika. Esto no significa que con las categorías de una lengua extraña podamos describir mejor la lengua propia, porque lo que hacemos no es equiparar categorías y recursos morfosintácticos, sino integrarlos en un esquema superior.

Todas las lenguas son realizaciones de la misma capacidad para la actividad verbal que llamamos lenguaje, pero no son copias de un mismo prototipo como los carros o las litografías. El lenguaje humano se realiza en cada lengua particular, pero no plena o exhaustivamente en ninguna de ellas, por lo que ninguna lengua particular puede servir para entender plenamente otra. Solo podemos lograr un conocimiento adaptado si nuestro entendimiento se ajusta a los dos principios complementarios de asimilación y acomodación. La acomodación a las diferencias que observamos en otra lengua se logra modificando y diversificando los esquemas mentales, que así mejoran su capacidad asimilativa. El método contrastivo ayuda a percibir una complementariedad entre las coincidencias y las discrepancias, generando un esquema de orden superior que sirve de tertium comparationis. Es necesario combinar dinámicamente ambas perspectivas.

En el desarrollo de la gramática didáctica del wixárika confrontamos esta lengua con el castellano (y otras lenguas) tomando en consideración las características que comparten y también aquellas en que no coinciden, para impedir que cualquiera de las lenguas sea utilizada como modelo de la otra. La intención principal de la Gramática Didáctica del Huichol es capacitar a hablantes nativos para la reflexión sobre su propia lengua y la enseñanza efectiva de la misma en la escuela. Los escasos conocimientos gramaticales que los maestros han adquirido tienen que ver con castellano y no con wixárika, lo que lejos de ayudar constituye un obstáculo de salida para reflexionar sobre su lengua. Nuestro método facilita la comprensión de las dos lenguas porque no genera falsas equiparaciones ni transmite tampoco la idea de que son inconmensurables.

El método contrastivo favorece una reflexión metalingüística que ayuda tanto a los hablantes competentes de una lengua a entender e incluso a descubrir características particulares de la misma como a quienes tratan de aprenderla desde la competencia gramatical de otra lengua. 


\section{El programa integrado de la lingüística operacional}

La descripción de una gramática particular, la comparación contrastiva, la tipología y la universalística deben formar un programa integrado y no etapas sucesivas de acercamiento al fenómeno del lenguaje, porque las propiedades particulares de una lengua, las compartidas por varias y las universales se articulan de manera circular en cada lengua. Este programa integrado es la base de la lingüística operacional, desarrollada en la Universidad de Colonia por el grupo UNITYP bajo la dirección de Hansjacob Seiler.

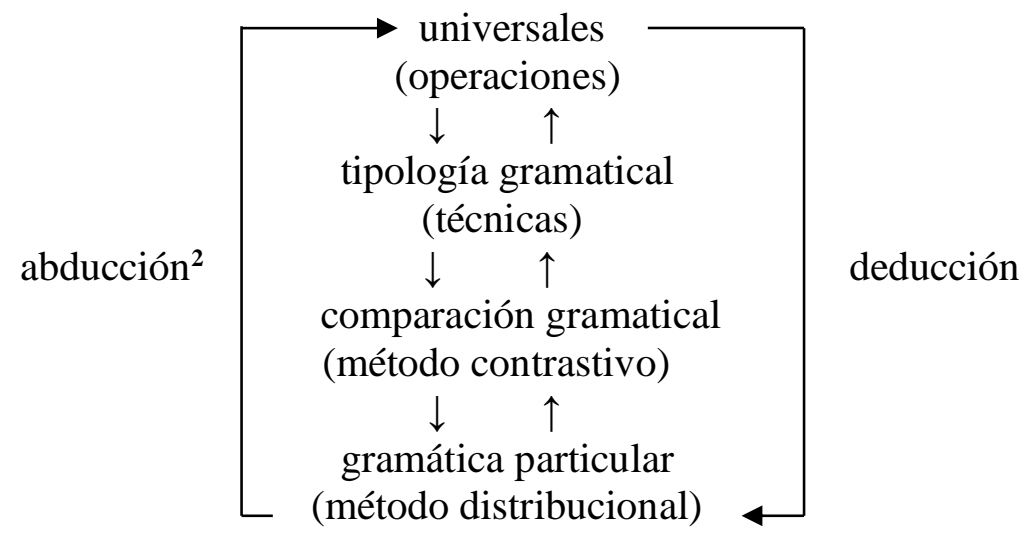

Diagrama de flujo circular del programa integrado

Ninguno de los niveles precede estrictamente a otro; no hay un principio ni un final absoluto dado que se trata de un flujo circular. Los niveles de análisis no se deben entender ni aplicar secuencialmente de manera que solo cuando se haya concluido uno se pueda empezar con el siguiente, sino de manera circular, en un proceso de ida y vuelta. Los diferentes dominios se interrelacionan en un flujo circular.

No se puede cerrar la descripción de una lengua particular sin la comparación con otras lenguas. Solo así puede constituir una aportación a la gramática comparativa y preparar el terreno para el análisis tipológico y el establecimiento de universales. El método contrastivo no es simplemente una extensión del método distribucional intralingüístico, es al mismo

2 Peirce (Collected Papers 2, 643) la entiende como la primera etapa de un proceso inductivo caracterizada por la elección de una hipótesis para explicar observables empíricos. 
tiempo un adelanto del análisis tipológico. No hay que esperar al nivel tipológico para hacer comparables dos gramáticas particulares, pero una vez que la tipología ha establecido marcos conceptuales para la comparación, se deben aprovechar para la descripción de las lenguas particulares. En cada nivel hay que seguir dos procedimientos complementarios; uno abductivo (inductivo), que canaliza datos relevantes hacia arriba para construir en un nivel superior un nuevo tipo de conceptualidad más abstracta, más holística, más operativa, y otro deductivo, que proyecta estos nuevos esquemas hacia el nivel inferior para llevar a cabo una descripción más precisa y abarcadora. Así se va construyendo una conceptualidad que sirve de tertium comparationis entre dos niveles cualesquiera, conectándolos y acoplándolos.

Aprendemos a reflexionar mejor sobre una lengua cuando la comparamos con otra. Las deformaciones que produce el contemplar una lengua a través del prisma de otra se contrarrestan con la aplicación recíproca de este procedimiento, con el doble efecto de que la lengua ajena se hará menos extraña a la par que la propia causará extrañeza. La comparación contrastiva es tan beneficiosa para la descripción de estructuras particulares como la descripción cada vez más rica y ajustada de gramáticas particulares nutre y enriquece la comparación interlingüística, en un movimiento siempre circular, es decir bidireccional.

Las reflexiones surgen de un trabajo intenso de más de 30 años con varias lenguas amerindias, especialmente wixárika, náhuatl y miphaa (tlapaneco), donde tratamos de evitar que la descripción esté condicionada por la gramática del castellano o de cualquier otra lengua. La elaboración de las gramáticas respectivas combina la actividad descriptiva de las estructuras particulares con la comparación contrastiva, tipológica y universalística (Iturrioz el al. 2001, Iturrioz y Gómez 2006, Iturrioz, 2014, Iturioz y Martínez 2021).

Para la mayoría de los lingüistas, la descripción de gramáticas particulares y más aún la comparación de las mismas requiere un marco teórico, es decir una teoría lingüística. Haspelmath (2010) sale al paso de estas afirmaciones alegando que las lenguas particulares deben ser descritas en sus propios términos porque cada lengua tiene sus propias categorías, y los marcos teóricos contienen presupuestos apriorísticos, preconcebidos que van a prefigurar y hasta distorsionar la descripción. Solo en el nivel tipológico se deben introducir nuevos términos que hagan comparables las descripciones particulares. En su opinión, la 
mejor primera clase de sintaxis para estudiantes es un curso de métodos de trabajo de campo, y la segunda mejor clase de sintaxis es un curso de tipología.

If we want to understand the nature of syntax, we have to study the syntactic patterns of concrete languages, preferably unfamiliar languages, to broaden our horizons [...] learn to compare languages with diverse categories by means of universally applicable comparative concepts. (Haspelmath 2010: 18-19)

La razón de esta propuesta radical es que

A framework (also called descriptive framework, or theoretical framework) is a sophisticated and complex metalanguage for linguistic description that is intended to work for any language. (Haspelmath 2010: 2)

Parece tratarse de fases o etapas con solución de continuidad. La primera fase se presenta como un salto al vacío; el trabajo de campo se tendría que hacer en una absoluta desnudez conceptual, libre de cualquier interferencia con las categorías de cualquier otra lengua para evitar ver la lengua que se pretende describir a través del prisma de otra.

Para Haspelmath, el desarrollo de conceptos que permitan llevar a cabo comparaciones y buscar universales comienzan en la tercera etapa. Pero ¿cómo se transita de la descripción inconexa, desarticulada de gramáticas particulares a la tipología? ¿Qué garantiza que las gramáticas elaboradas con independencia de cualquier marco teórico sean comparables en la fase tipológica? La comparación interlingüística enlaza ambos niveles. El mismo Haspelmath rebaja la vehemencia de su propuesta inicial:

the recognition that each language has its own categories does not mean that one cannot learn from other languages, because languages tend to exhibit great similarities in their categories and grammatical patterns. (Haspelmath 2010: 7)

Saltando de un extremo al otro, afirma que las similitudes entre las lenguas pueden ser tan fuertes que 
A linguist who has studied twenty (frameworkfree) grammatical descriptions of different languages will find the twenty-first language description fairly easy to follow, because there will be much that looks familiar from earlier descriptions. (Haspelmath 2010: 7)

Por grandes que sean las similitudes solo pueden hacerse patentes a través de un sistema conceptual que las hace comparables. Para reconocer las similitudes utiliza conceptos como palabra, nombre o palabra referencial, verbo o palabra predicativa, tiempo, aspecto, modo y muchos más. Si acepta que nada se opone a equiparar una clase de palabras que denota en inglés individuos y objetos y una clase de palabras semánticamente similar en tagalo, deja sin fuerza la exigencia inicial de describir las lenguas en términos distribucionales, y apoya la conveniencia de recurrir a un marco teórico básico, propuesto por algunos autores como Dryer (2008) y Dixon (2010: 128-138), una teoría lingüística básica que pueda servir para un primer acercamiento a las lenguas.

Con respecto a la pretensión de que tras 20 descripciones de lenguas libres de cualquier marco teórico, en la 21 no cabe esperar muchas ni grandes sorpresas, hay que precisar que depende de las lenguas elegidas y de la profundidad con que se hayan podido hacer las descripciones sin ayuda de un marco teórico. El conocimiento previo de más de 20 gramáticas descriptivas, a pesar de no ser puramente distribucionales, no sirvió mucho para emprender la tarea de describir la gramática del wixárika, del náhuatl o del miphaa. Sin embargo, el conocimiento previo del wixárika allanó el camino para la descripción del náhuatl, mientras que el conocimiento de estas dos lenguas no facilitó la tarea de describir la gramática del miphaa. La existencia previa de una descripción distribucional del wixárika (Grimes, 1964), no nos ayudó para detectar en esta lengua un fenómeno gramatical complejo, aunque sencillo en comparación con otros, como el sistema de clases nominales, pero sí sirvieron descripciones previas de lenguas caucásicas o bantúes y sobre todo estar familiarizados con el marco teórico UNITYP de orientación tipológica y universalística.

No se puede dar un salto de las gramáticas particulares a la tipología y los universales. Primero se requieren análisis comparativos o contrastivos entre lenguas. La descripción de una gramática particular arroja luz sobre otras lenguas que a su vez ayudan a descubrir y entender mejor la primera. Los resultados de la comparación pueden ser tan beneficiosos para la descripción de estructuras particulares, como la descripción cada vez más rica de 
gramáticas particulares nutre y enriquece la comparación interlingüística. El avance en la descripción de gramáticas particulares es una condición para progresar en el dominio de la comparación, de la tipología y de la búsqueda de universales. A la inversa, los avances en estos dominios se deben traducir en una mejora de los métodos descriptivos. Para que los datos de una gramática particular puedan ser útiles para la comparación gramatical, la tipología y la universalística, deben ser construidos desde una teoría de orientación comparativa, tipológica y universalística.

La comparación contrastiva abre las puertas a la tipología, por la que deja de ser una pura acumulación de datos aislados procedentes de las gramáticas particulares; ordenando estos datos de acuerdo con ciertos parámetros comparativos, la tipología da cuenta de las afinidades selectivas y de las complementariedades. Los universales se obtienen por la observación de invariantes funcionales en la variación tipológica.

En la construcción de una operación como INDIVIDUACIÓN ${ }^{3}$ la categoría 'nombre' es representada como un continuo de nominalidad (nivel universal) en el que se ordenan de acuerdo con una batería de parámetros una serie de técnicas (nivel tipológico) con una función común, la aprehensión lingüística del objeto, para cuya realización las lenguas emplean recursos morfosintácticos diferentes. Este continuo universal de nominalidad se manifiesta en la comparación de lenguas e incluso en las gramáticas particulares. Voy a ilustrar mediante un ejemplo sencillo el poder explicativo del continuo de nominalidad. En wixárika el nombre prototípico puede ir acompañado de posposiciones que expresan esquemas espaciales o temporales (-tsie "sobre"), causa o instrumento (-ki): 'ipari-tsie

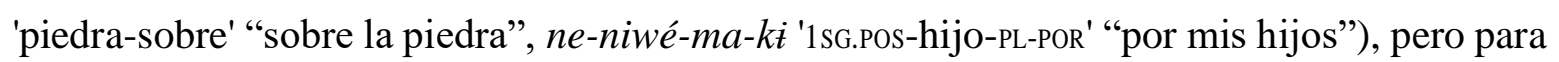
que un determinante atributivo pueda llevar una posposición se requiere incrementar su grado de nominalidad mediante el nominalizador débil -me, que no llega a formar derivados. Tsipeme no se sustenta en sí mismo, la presencia de - me solo es condición para que pueda añadirse un morfema espacial.

(1) ${ }^{2}$ Ipari tsipe -me -tsie. (*tsipe-tsie)

3 Es la operación más básica constitutiva de la nominalidad, que hace posible el conteo (de individuos) y por oposición la medición. Es una de las operaciones mejor estudiadas en la Universidad de Colonia (Alemania) por el grupo UNITYP y posteriormente en la Universidad de Guadalajara (México). 
equipal chico $\mathrm{NOMR}_{\mathrm{X}}$ sobre

"Sobre un equipal chico."

Este - me es una instancia particular de una escala de casi 20 variantes que corresponden a otros tantos tipos de estructuras, una de las cuales es la ilustrada en (1). Los integramos en una familia de exponentes globales $-\mathrm{ME} 1 \leq \mathrm{X} \leq \mathrm{n}$, cada uno de los cuales indica un grado de nominalidad en la escala y un tipo de estructura cada vez más compacta o condensada, es decir más nominalizada (Iturrioz 2021). En castellano el y lo pueden fungir también como nominalizadores débiles ante estructuras determinativas y con cláusulas completas (ver más abajo) sin que puedan ser equiparados a ninguna instancia de -me desde un punto estructural.

A continuación voy a mostrar con varios ejemplos cómo se puede llevar a cabo un análisis contrastivo que ayude a superar las deficiencias de descripciones previas resultantes de equiparaciones precipitadas con fenómenos "similares" de otras lenguas.

\section{Análisis contrastivo del "artículo" en castellano, euskera y náhuatl}

Desde los primeros estudios gramaticales, la descripción del euskera (vasco) ha estado sometida a la gramática del castellano. El sufijo - $a$ que acompaña con mucha frecuencia a los sintagmas nominales (etxe-a "casa", etxe berri-a "la/una casa nueva", etxe berri haundi-a "la/una casa nueva grande") ha sido identificado con el artículo determinado del castellano. Ambos aparecen al final del sintagma, - $a$ en la última posición posnominal, el artículo castellano casi siempre en la última posición prenominal; lo que a primera vista parece una diferencia, es en realidad una similitud especular. Una diferencia más importante es que $-a$ es un sufijo, a pesar de lo cual tiene la misma movilidad que el artículo, cuyo estatus gramatical es de clítico. Ambos son incompatibles con los demostrativos, lo que muestra que tienen que ver con la función referencial. Pueden ir seguidos de la marca de plural: lo-s, etxe$a-k$ "las/unas casas". La ausencia de $-a$ significa que el nombre no es singular ni plural, sino transnumeral.

(4) Aurten ba-da udare "Este año (sí que) hay (buena cosecha de) manzana."

Y alterna con el partitivo en cláusulas negativas o con el irrealis: $e z d u t$ diru(r)ik "no tengo 
dinero", diru(r)-ik izan-go n-u-ke "me gustaría tener dinero" frente a diru-a izango nuke. La diferencia no corresponde a la oposición determinado/indeterminado.

La diferencia más importante es que etxe berri-a puede traducirse, según el contexto, como "la casa nueva" o como "una casa nueva". La oposición [ \pm definido] es irrelevante para - $a$, cuya función primaria no se inscribe en la operación de identificación, sino en la operación más básica de individuación (Iturrioz, 1985).

(2)Islandia-n ur bero-a bota-tze-n d-u-te-n iturri-a-k ba-dira.

Is1. -LOC agua cal.-IND echar-NOM-LOC ABS3-AUX2-PL-DET fuente-IND-PL AS-AUX1.PL

"En Islandia hay fuentes que echan agua caliente."

(3) Koldo zurgin-a. "Koldo es carpintero/el carpintero/un carpintero."4

El morfema - $t$, que se sufija a la mayoría de los nombres 5 (nawa-tl "la lengua náhuatl", konee-tl "niño, hijo", meka-tl "mecate, cuerda"), también ha sido equiparado al artículo. Como en euskera, se sufija siempre al nombre. Puede coocurrir en el sintagma nominal con un pronombre demostrativo, lo que indica que su función primaria no es primariamente referencial: ni koskatsopilo-tl "este zopilote", nopa koneetl "ese niño", nopa kostli "ese collar", ne xahkalli "aquel jacal”. Esto no ocurre en euskera. Es incompatible con los morfemas de posesión, a diferencia de euskera y en coincidencia con castellano: no-kos $(* t l i)$ "mi collar", nokoone (*-tl) "mi niño", no-xahkal(*li) "mi jacal", kehne ne no-cha "para esta mi casa" (chan-tli "casa, hogar"). ${ }^{6}$ En castellano el artículo puede coocurrir con un pronombre demostrativo o posesivo solo si va pospuesto en calidad de determinante atributivo, dejando así libre la posición del artículo y otros determinantes fuertes: el coche aquel, el alma mía. Algunas gramáticas llaman a - tl absolutivo por entender que es la marca del estado absoluto por oposición al estado constructo con presencia de morfemas de posesión: meka-tl "mecate" vs. no-meka "mi mecate". Solo aparece en ausencia de un morfema de plural (totoo-tl - totoo-meh “pájaro-s?", siwa-tl - siwa-meh “mujer-es", lo que

4 La difusión entre los nuevos hablantes del numeral bat "uno" como artículo indeterminado etxe berri bat "una casa nueva" es un calco del castellano que sirve para ajustar más el euskera al castellano, lo que incide negativamente en la estructura tradicional del euskera (Iturrioz 1985).

5 No lo llevan los préstamos de otras lenguas y otras clases menores de nombres.

$6-t l$, - $t l i$ y $-l i$ son variantes combinatorias, fonológicamente condicionadas. 
no significa que sea una marca de singular. Con los nombres inanimados, que son transnumerales, $-t l$ es indiferente al número, y es por ello compatible con los numerales ( $e y i$ meh tlapitsan-eh "tres músicos"), incluido se "uno", que no se puede considerar como artículo indeterminado ya que puede coocurrir en la misma frase con el supuesto artículo determinado: 'ipan se weyi 'altepe-tl "en una gran ciudad", 'eyi kaxi-tl "tres platos" (*'eyi kaxi). También aparece - $t l$ en las construcciones de medición, tanto en el mensurativo como en el nombre de masa ('eyi komi-tl 'aatl "tres ollas de agua"), a diferencia de castellano (dos vasos de agua) y euskera (bi edalontzi ur) o alemán (zwei Glas Bier), donde los nombres aparecen en trasnsnumeral. En suma, tanto el artículo castellano como - $a$ en euskera y $-t l$ en náhuatl son indicadores de nominalidad, pero en cada uno predomina una función diferente: determinación en castellano, individuación en euskera y posesión en náhuatl. Cada uno presenta un cuadro distribucional diferente y funciones complementarias.

Cabe preguntarse si el paradigma del artículo en castellano se compone de tres elementos. Lo se sigue considerando en la filología castellana como la forma neutra del artículo. Pero hay diferencias importantes entre lo y las otras dos formas. El antecedente de lo no es una frase nominal (no hay sustantivos neutros). Por su distribución, lo no encaja en el paradigma de los artículos. Mientras el y la acompañan al nombre, del que toman el género y el número, lo va seguido en general de expresiones que no son nombres y por lo mismo carecen de género y número, por lo que no se puede hablar de concordancia: me atrae lo nuevo, que no se repita lo de ayer, no me creo lo que cuenta, me choca lo descaradamente que miente. Puede anteponerse a un nombre o adjetivo de género masculino o femenino, en singular o en plural sin que se produzca concordancia: me sorprendió lo sana que se ve, a pesar de lo oscuros que fueron esos momentos. Si no se antepone a un nombre y el resultado sí tiene un comportamiento sintáctico nominal, entonces se trata de un nominalizador. (Iturrioz 1987b)

Lo aparece también antepuesto a estructuras no determinativas, utilizadas con frecuencia en el presente texto:

(11) Sus escasos conocimientos gramaticales tienen que ver con castellano, lo que lejos de ayudar constituye un obstáculo para reflexionar sobre su lengua. 
(12) Puede coocurrir en el sintagma nominal con un pronombre demostrativo, lo que muestra que no tiene función referencial.

(13) El lenguaje humano no se realiza plenamente en ninguna lengua, por lo que ninguna puede servir para entenderlo plenamente.

(14) No son nombres, carecen de género y número, por lo que no se puede hablar de concordancia.

Cuando la cláusula no tiene una posición vacía, el antecedente de lo no hay que buscarlo dentro de la cláusula subordinada, sino fuera de ella, y no puede tratarse de una FN canónica, sino del contenido proposicional de la cláusula precedente, retomada mediante un pronombre anafórico neutro: por [lo [que [no se puede hablar de concordancia]]]. Sin ese componente anafórico, la causa sería expresada por la subordinada: por [que [no se puede hablar de concordancia]].

También $e l$ abre la posibilidad de que una oración asuma la función de un argumento: el [que [Juan lo afirme]] no significa que sea verdad. La oposición entre el y lo difiere mucho de las oposiciones que constituyen el paradigma de los artículos prenominales; $e l$ se antepone a una cláusula sustantiva para topicalizarla.

Hay otra estructura en la que una cláusula sustantiva puede aparecer como determinante de un nombre, de lo o un pronombre demostrativo, lo que muestra que ambos signos (lo y que) no constituyen una unidad, sino que cada uno de ellos hace una aportación propia a la misma:

(15) El hecho de que corresponde igualmente al artículo indefinido...

(16) El PSOE volverá a manejar lo de que viene la derecha. (CREA)

(17) Vayamos con cuidado con eso de que era un estadista. (CREA)

(18) No suelen tener una infancia muy feliz por aquello de que sus padres están muy poco con ellos. (CREA)

(19) Yo no quiero meterme en esto de que si las actas son o no auténticas. (CREA)

En estos casos se trata de oraciones "sustantivas", como lo muestra el contraste con la frase siguiente, que corresponde a una cláusula relativa.

(20) Esto de que voy a hablar ahora es muy importante. (CREA) 
Lo que acabamos de hacer es un pequeño ensayo de análisis contrastivo entre los artículos en la frase nominal y en el nivel de la oración. Se trata de una relación analógica similar a la que existe entre la determinación atributiva y las cláusulas "adjetivas" (determinativas) así como entre la frase nominal cerrada y una oración "sustantiva". Las estructuras son diferentes y las reglas que rigen el uso de los artículos también.

\section{Análisis contrastivo de las cláusulas determinativas.}

En la vigésima primera edición del Diccionario de la Lengua Española de la RAE todavía se seguía considerando en las gramáticas del castellano a que como un pronombre relativo, diferente del que subordinador.

Que. Pronombre relativo que con esta sola forma conviene a los géneros masculino, femenino y neutro y a los números singular y plural. Con el artículo forma el relativo compuesto: el que, la que, lo que, los que, las que que a diferencia de la sola forma que, posee variación de género y número y puede construirse en concordancia con el antecedente.

Más que "convenir" a los 3 géneros y a los 2 números, las categorías de género y número le son ajenas. La combinación el que, las que implica que que no es un pronombre, ya que el artículo no se puede combinar con un pronombre, que por definición reemplaza a todo un sintagma nominal. La variación de género y número pertenece a el, la, las, los, formas del artículo que se anteponen no a que, sino a las oraciones relativas, también llamadas adjetivas, con la misma función que ante los adjetivos: el mencionado, las descritas.

En la más reciente edición $23^{\mathrm{a}}$ del DRAE se abandonó la idea de que una única forma conviere a los tres géneros, pero se mantienen otras no menos extrañas:

1. es un pronombre que introduce una oración relativa con o sin antecedente (el que estaba en el escaparate)

2. se confunde con el interrogativo tónico qué (no tiene qué leer)

3. como conjunción introduce una oración subordinada sustantiva.

Todavía hoy no existe una gramática del castellano que se haya desmarcado totalmente de la gramática del latín en este y en muchos otros puntos. En la Nueva Gramática de la Lengua Española se repiten esos y otros errores. 
En el libro que lees, el pronombre relativo que desempeña la función de complemento directo del verbo leer... La relación anafórica que se establece entre que y libro... permite que la oración de relativo se interprete como un modificador restrictivo del sustantivo libro. (NGLE, 2009:1558)

Parece que se está hablando de latín quem / quam / quod y no de la palabra invariable del castellano que. En latín existe un verdadero pronombre relativo, que copia del nombre antecedente algunas propiedades como el género y el número, mientras que en castellano hay un subordinador que sin propiedades pronominales.

(4) Uides istos, qui eloquentiam laudant?

ves a estos que elocuencia alaban

“Ves a esos que alaban la elocuencia?”

En latín sabemos que el antecedente del pronombre anafórico qui es istos porque copia el género y el número de esta palabra: es masculino plural y está en el caso nominativo, que corresponde al rol sintáctico del elemento extraído. Por el contrario, si que no tiene género ni número ni caso no es un pronombre y por lo mismo no puede tener una función anafórica ni asumir el rol sintáctico del núcleo del sintagma nominal extraído de la cláusula. Los errores descriptivos que resultan de describir las oraciones de relativo en castellano como si se tratara de las latinas, nos retrotraen a una etapa preestructuralista, anterior al análisis distribucional. Afirmar que que conviene a los tres géneros y a los dos números, sugiere que puede pronominalizar a cualquier sintagma nominal, cuyo núcleo nominal puede ser masculino, femenino o neutro, singular o plural, aunque no lleva ninguna marca de género ni número que permita identificar al antecedente. La única propiedad que conserva es la de relativo, es decir de conector estructural, más específicamente subordinador.

Que no se trata de un pronombre anafórico, se manifiesta en la tendencia de los hablantes a introducir un verdadero pronombre en las relativas, que suple la información no proporcionada por el subordinador:

(5) Son instrumentos que nosotros no los ocupamos, pero que nuestros hijos ocupan.

(6) Esta va a ser una Constitución impuesta que no la vamos a acatar.

(7) Es un problema que nos parece fundamental indagarlo. 
(8) Es un hombre solitario que su destino está en contra de él.

Otra solución consiste en anteponer un verdadero elemento anafórico, que retoma algunas de las propiedades morfosintácticas del antecedente, justamente para poderlo identificar sin ambigüedad, cuando el antecedente queda un poco lejos:

(9) Para ilustrar los nexos entre el Ejército Mexicano y los narcotraficantes, se trasmiten las imágenes del enfrentamiento entre militares y policías judiciales, ocurrido en noviembre de 1991, en Tlalixcoyan, Veracruz, las cuales / mismas que / las que fueron filmadas desde un avión de la DEA.

Precisamente la ausencia de rasgos pronominales en el subordinador castellano desata la presencia de un artículo o la aparición de una verdadera anáfora pronominal en la cláusula. Esta solución solo es posible en el caso de las oraciones no restrictivas, que tienen mayor autonomía sintáctica (son apositivas), lo que entre otras cosas permite hacer una verdadera referencia anafórica al sintagma nominal antecedente. Ahora bien, solo cuales, mismas y las tienen propiedades morfosintácticas que les permiten establecer una relación anafórica.

En el español coloquial, que se puede presentar cuando no ha sido extraído de la cláusula un argumento vacío con el que pudiera estar en una relación de anáfora. Este tipo de construcción no permite distinguir entre una configuración determinativa y una completiva.

(10) La trata de mujeres y de niñas es un problema sin fronteras, de grandes dimensiones, pero que ahora te diste a la tarea de recorrer varios lugares para investigar las redes y las rutas.

Lo que constituye una cláusula determinativa ("relativa", "adjetiva") es que tiene una posición vacía, que hace posible utilizarla como determinante para identificar al argumento faltante: el / la x -x habla (el/la que habla), lo x - el orador dijo x (lo que dijo el orador).

$\mathrm{El}$ "pronombre relativo" es considerado como diferente del que subordinador, definido en el DRAE como

conjunción copulativa cuyo oficio es introducir una oración subordinada sustantiva con función de sujeto o complemento directo. Quiero que estudies; recuerda que eres mortal; dijo que lo haría. (DRAE) 
En castellano no se puede establecer una oposición entre ambos que con respecto a ninguna de las categorías morfosintácticas mencionadas, las categorías de género y número son ajenas a ambos. Las diferencias se ubican en las construcciones sintácticas como tales; en las determinativas, que subordina una cláusula con una posición vacía a un nombre o a una frase nominal, asumiendo un papel de determinante; en las sustantivas, que subordina una cláusula completa a un verbo; la cláusula relativa tiene un argumento vacío que corresponde a la frase nominal que la encabeza, mientras que la completiva o sustantiva tiene la función de un argumento en la cláusula principal y como los sustantivos (típicos) está saturada, no tiene valencia abierta. Las diferencias contextuales no se deben proyectar sobre el conector mismo, estableciendo una oposición entre dos categorías que no tiene soporte en su comportamiento morfosintáctico. El conector que es idéntico en ambos casos (en las cláusulas determinativas y en las completivas), no hay ninguna propiedad inherente que los distinga, lo que cambia son otras propiedades del entorno sintáctico, es decir la configuración de indicadores en su conjunto.

En náhuatl, las clausulas relativas (determinativas) van precedidas por tlen, que es el operador de determinación por excelencia.

(21) Chiyawalli tlen kaxi-tl mo-pahpaka 'ika limo 'i’aayo. grasa DET plato-ABS REFL-lavar con limón 3POS-jugo "La grasa de los platos se quita con el jugo del limón/de los limones."

En varios aspectos es equiparable a cast. de, en otros no. En la traducción al castellano de aparece tanto para tlen como para la relación de posesión inherente entre el limón y el jugo, donde el náhuatl utiliza una construcción de posesión inalienable. De hecho, de se usa en una gama menos amplia de relaciones semánticas entre las frases nominales.

(22) 'I-pan sempowali tonal-li tlen ni meets-tli.

3POS-sobre veinte día-ABS DET D1 mes-ABS

"En los 20 días de este mes."

(23) Kwa-tineh tlen ni tlaaltipak tech-'akawilmaka-h. árbol-PL de D3 tierra 1PL.OBJ-sombra-dar-PL 
"Los árboles de la tierra nos dan sombra."

Si la relación no es entre dos entidades preestablecidas, sino entre dos conceptos (intensional), tlen no se puede emplear. Se rebasa el dominio de la operación de DETerminación y entramos en el dominio de la formación de términos (y conceptos). Pero en castellano se sigue empleando de en esos (jugo de limón, maestro de primaria) y otros casos de relación metalingüística como la ciudad de Madrid, el nombre de Pablo, la categoría de nombre, un palo de manzano, donde náhuatl recurre a la composición: sokikaxitl 'barro-plato-ABS' "platos de barro", tete-pami-tl 'piedra pared-ABS' "pared de piedra", 'ichka-yoyomitl 'lana-camisa-ABS' “camisa de lana”. Tamalli tlen piyo es un calco del castellano en lugar de piyo-tamal-li 'pollo-tamal-ABS' "tamal de pollo". A diferencia de puerta tlen teposkawayul "a puerta del carro" (parte de un todo), la palabra tepoz-kawayu significa "carro, coche" (lit. "caballo de metal”). A diferencia de la construcción posesiva no-kal 'i-puerta' mi casa '3SG.POS-puerta' "la puerta de mi casa", kal-tsakayotl es un compuesto de kalli "casa" y tsakayotl "tapón, tapadera", que significa un tipo de tapadera, igual que kal-puerta. Las construcciones que designan una relación parte-todo no quedan fuera del alcance del operador tlen, también se puede decir puerta tlen nokal "la puerta de mi casa”. Aquí todavía se trata de dos entidades relativamente independientes, mientras que el plato no existe sin el barro ni la camisa sin la lana. El compuesto kawayo-tlankoch-tli 'caballo-dentadura-ABS' “dentadura de caballo” no se refiere a ningún caballo particular, tlankoch-tli tlen kawayu 'dentadura-ABS de caballo' "la dentadura del caballo" es una estructura determinativa, que restringe la extensión del nombre núcleo, y kawayu 'i-tlankoch es específicamente posesiva, y la más apta para expresar relaciones inherentes.

La frase siguiente expresa la extracción de ejemplares a partir de un conjunto mayor, que es la base de la operación determinativa de restricción referencial.

(27) ? Ahkeya tlen 'inmohwantih tech-palewi-s. quién det ustedes 1PL-OBJ-ayudar-FUT “¿Quién de ustedes nos ayudará?" 
Cuando no restringe la extensión de otro sustantivo, hace que el sustantivo que encabeza designe solo una parte de su dominio referencial: significado partitivo. Este significado es ajeno a de. (28) no se refiere a todos los perros, sino solo a una parte: una raza o ejemplares particulares, según el contexto.

(28) Tlen ni chichimeh ni kwali yolkameh, ’axkema mits-katewa-s-eh.

Part D1 perro-PL D1 bueno animal-PL, nunca 2SG.OBJ-abandonar-FUT-PL

"Estos perros son buenos animales, nunca te abandonarán."

Las cláusulas introducidas por tlen son restrictivas (especificativas), es decir restringen la referencia de la frase nominal que encabeza el sintagma nominal;

(29) Chichi-meh tlen 'ax-ki-piya-h 'ininteko san neh-nen-ti-nemi-h perro-PL DET NEG.OBJ-tener-PL 2PL.POS-dueño nomás RED-andar-comp-andar-PL NE ?ohti-pan.

D3 CAMINO-LOC

"Los perros que no tienen dueño nomás andan vagando por las calles."

Si no se quiere restringir la referencia se recurre a una estructura no insertada en el sintagma nominal, apositiva, coordinada o subordinada (explicativa).

(30) Chichi-meh kwali mo-wika-h ? 'inin-waya tlaka-meh, 'axkema ki-in-kawa-h. perro-PL bien REFL-llevar-PL 3PL.POS-con persona-PL nunca 3SG.OBJ-PL-dej.-PL "Los perros se llevan bien con las personas, nunca las traicionan".

También se pueden usar sin encabezado, como en castellano. Pero a pesar de la equivalencia funcional entre estructuras, tlen no equivale ni a de, ni al artículo ni a que.

(31) Tlen tla-pihpiya-h 'inin-mila.

Part GEN-cuidar-PL 3PL.POS-milpa

"Los que cuidan su milpa." 
En wixárika, no hay un morfema especial que identifique inequívocamente a las cláusulas determinativas. Una condición necesaria, pero no suficiente es la presencia del modal $m \dot{t^{-}}$. Mientras $p \dot{t}$ - caracteriza la información como de primera instancia, donde el hablante avala con su propia experiencia la veracidad del contenido proposicional, el modal $\mathrm{mi}$ - da a entender que la información procede de una fuente secundaria de evidencialidad (de oidas, conocimiento colectivo, inductivo, memoria); reduce la asertividad, y se usa a menudo por cortesía, para no parecer impositivo, en fin por razones de pragmática comunicativa (Gómez 2013). La cláusula siguiente describe una experiencia compartida que incluye al oyente y podría interpretarse como un enunciado genérico a no ser porque el morfema espacial hasignifica que la voz de la paloma llega hasta el lugar donde se está conversando. Se puede entender como determinativa, pero entonces se requeriría una cláusula principal.

(32) Kukurú m-a-tsuaka. paloma SEC-CISL-llorar "La paloma (que) se oye llorar."

Aparece obligatoriamente en cláusulas subordinadas, entre ellas las determinativas, y facultativamente en cláusulas independientes caracterizadas como portadoras de información de fondo, de segundo plano epistémico. Otra condición necesaria, pero no suficiente, es que la frase nominal extraida de una posición argumental para que sirva de encabezado al sintagma nominal resultante debe ser por lo mismo pronominalizada en el verbo, como en (33) b. se pueda entender como determinativa, la frase nominal topicalizada

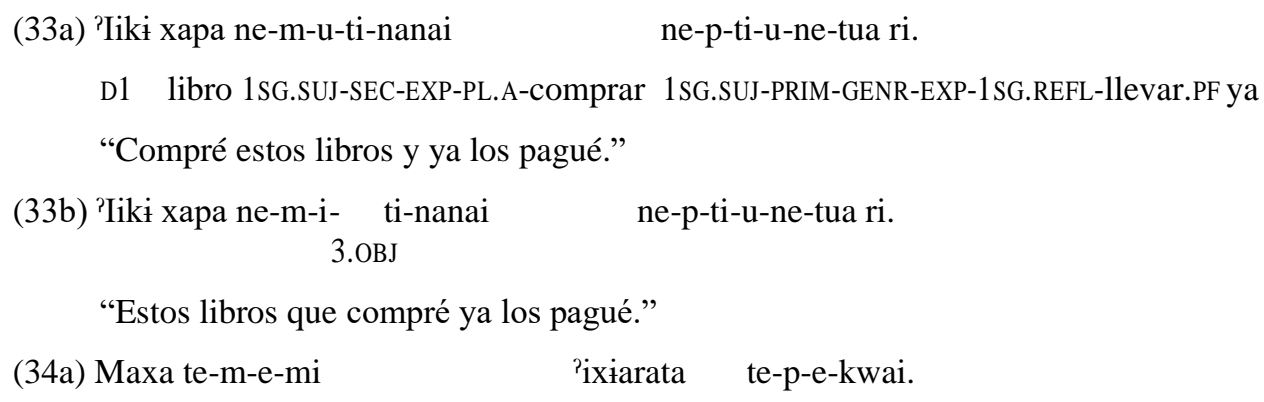


venado 1PL.SUJ-SEC-NEXP-matar.PF en.la.fiesta 1PL.SUJ-PRIM-NEXP-comer.PF

"Matamos y comimos un venado en la fiesta."

(34b) Maxa te-m-e-i- mi 'ixiarata te-p-e-kwai.

3OBJ

"El venado que cazamos lo comimos en la fiesta."

En euskera las cláusulas determinativas se construyen con el morfema -en (determinativo posesivo, llamado genitivo) que es uno de los recursos para conectar frases nominales: Koldo(r)en etxe-a "casa de Koldo"; el otro es el delimitativo - $k o$, así llamado por su significado básico espacial: etxe-ko andre-a "casa-DEL-señora-IND" "ama de casa".

(35) Aita-(r)en baserri-ko ate-a-(r)en kolore-a.

padre-POS caserío-del puerta-IND-POS color-IND

"El color de la puerta del caserío de (mi) padre."

(36) Uztail-(e)ko egun-eta-ko eguzki-a-(r)en beroa.

agosto-DEL día-PL-DEL sol-IND-POS calor

"El calor del sol de los días de agosto."

Ambos morfemas - en y -ko participan de una manera análoga en la construcción de cláusulas determinativas y completivas.

(37) Nere ait(a)-a-k erosi du-en etxe-a.

mi padre-IND-ERG comprado AUX1-DET casa-IND

"La/una casa que ha comprado mi padre."

(38) NOR lagun bat baino gehiago d-en-(e)ko eskema hartu behar d-u-gu.

cuál rol uno que más ABS-DET-DEL esquema tomar neces. ABS-AUX2-1PL

“Tenemos que tomar un esquema de donde el abs. designa a más de uno."

Ambos tipos de cláusulas (con - en y con -ko) se pueden sustantivar mediante el morfema - $a$, que es el signo de nominalidad por excelencia. 

(39) Esan z-u-n
etorri-ko e-tza-n-a.
decir ABSAUX2-PAS venir-FUT NEG-AUX1-REL-NOM
"Dijo que no vendría."

Latín, castellano, wixárika, euskera y náhuatl se comportan de manera complementaria en la formación de las oraciones de relativo. Ante esta diversidad estructural, la tarea del lingüista es explicar la equivalencia funcional dentro de la diversidad estructural, es decir la complementariedad. La igualdad no hay que buscarla en el nivel estructural, sino en el funcional. Las cláusulas relativas son una técnica determinativa, similar a los adjetivos atributivos, pero cada lengua utiliza recursos y estrategias diferentes para formar cláusulas relativas. Lo común a las cuatro lenguas no está en el nivel de las estructuras morfosintácticas, sino en el plano funcional. Ninguno de los dos morfemas se limita a una función (posesiva o delimitativa), sino que expresan cada uno una amplia gama de significados. Ambos participan en la construcción de cláusulas determinativas y en la nominalización de las mismas. Las coincidencias funcionales con el castellano y las otras lenguas no pueden soslayar las grandes diferencias morfosintácticas.

\begin{tabular}{l|l}
\hline Latín & ProN relativo \\
\hline Castellano & Subordinador que (+ ProN) \\
\hline Náhuatl & Operador tlen \\
\hline Wixárika & Asertor secundario $m i$ - + ProN \\
\hline Euskera & "Genitivos" $-e n,-k o$ \\
\hline
\end{tabular}

Esquema 1. Marcas de las cláusulas relativas

Este breve ejercicio contrastivo muestra cómo no se pueden transferir de manera indiscriminada las categorías de una lengua a otra. Las teorías lingüísticas y métodos descriptivos basados en una lengua no suelen ser adecuados ni siquiera para la lengua en la que se originan, mucho menos se pueden transferir a otras lenguas. Esto vale tanto para la gramática europea tradicional basada fundamentalmente en el griego y en el latín, como para la gramática tradicional japonesa o cualquier otra tradición lingüística carente de una dimensión comparativa. No es tanto la identidad cuanto la complementariedad lo que nos 
lleva a considerar estas estructuras como procedimientos alternativos dentro de la técnica determinativa de las cláusulas determinativas.

A estos resultados hemos llegado mediante un análisis contrastivo con el latín que pone de manifiesto notables diferencias morfológicas y sintácticas, pero también contrastando diferentes estructuras dentro del castellano en base a su distribución y a las oposiciones constitutivas; que se caracteriza por la falta de género, número y caso, lo que impide que haya concordancia con la cabeza de la cláusula, que conserve una huella del argumento extraído a través de una marca de caso, o que haga una referencia anafórica a una cláusula precedente.

\section{Análisis contrastivo de géneros y clases nominales}

Una razón que se podría aducir para hablar de declinaciones en náhuatl son las diversas maneras de formar el plural, a cuya descripción dedica Tapia varias páginas.

$\begin{array}{lll}\text { tlaca-tl } & \text { tlaka-me (persona) } & \text { animados, -meh } \\ \text { tamazol-li } & \text { tamazol-tin (sapo) } & \text { animales } \\ \text { toch-tli } & \text { to-toch-tin (conejo) } & \text { reduplicación y sufijo de plural -tin } \\ \text { cihua-tl } & \text { cihuatzitzin-tin (mujeres) } & \text { replicación del honorífico -tzin, -tin } \\ \text { theopixqui } & \text { theopixqu-eh (sacerdote) } & \text { agentivos } \\ \text { nota-tli } & \text { nota-huan (padres) } & \text { nombres de parentesco }\end{array}$

Esto da pie para otro ejercicio de análisis contrastivo de diferentes sistemas de clasificación de los nombres como las clases nominales en lenguas bantúes, caucásicas y yutoaztecas (al menos cora y wixárika), géneros y clases flexivas del español y otras lenguas (indo)europeas.

En wixárika, en naayeri (cora) y en náhuatl los nombres se clasifican por las distintas maneras de formar el plural, mientras que los géneros en latín se dan tanto en singular como en plural y son un factor determinante de la variedad de las declinaciones, en estas lenguas la clasificación de los nombres se manifiesta solo en el plural y está basada en otros rasgos semánticos. No existe una asociación con sexo; uno de los rasgos semánticos más destacados de las clases nominales es la oposición animado: inanimado, y una de las reglas más básicas es que los nombres inanimados no forman plural. Partiendo de estos datos, podemos establecer que existe una relación más intrínseca de clasificación nominal y número con la nominalidad. La interacción de número con diversos sistemas clasificación nominal 
constituye técnicas de individuación, intrínsecamente ligada a la nominalidad. Es la versión operacional de lo que Tapia formula ontológicamente al afirmar que los nombres son aquellas voces con que conocemos las cosas.

Como en español, los nombres huicholes expresan pluralidad mediante sufijos: piedras -teteé-xi. Junto a esta similitud hay una diferencia muy grande. En castellano, como en inglés hay un solo sufijo de plural: gatos, muros, aguas, girls, boys, houses. Existen algunas variantes condicionadas por el acento y otras propiedades fonológicas: árbol-es, bisturí-s o bisturí-es, bantú-s o bantúes, cafés o cafeses, mamás o mamases, bistés o bisteses, lunes, martes. Estas variantes no forman parte del sistema gramatical, están condicionadas por reglas fonológicas. Por el contrario, en wixárika encontramos diversas maneras de formar el plural con un significado adicional y en competencia.

En wixárika los nombres se clasifican mediante diferentes formas de marcar el plural, que expresan también diferentes ideas (Iturrioz et al. 1986a, Iturrioz 1986b, Iturrioz 1987a, b).

\begin{tabular}{|c|c|c|c|c|c|c|c|}
\hline -RI & $\begin{array}{l}{ }^{\text {}} \text { uká } \\
\text { tuutú }\end{array}$ & $\begin{array}{l}{ }^{2} \text { uká-ri } \\
\text { tuutú-ri }\end{array}$ & $\begin{array}{l}\text { mujer } \\
\text { flor }\end{array}$ & -RIXI & $\begin{array}{l}\text { tatsiu } \\
\text { tsiinú }\end{array}$ & $\begin{array}{l}\text { tatsiu-rixi } \\
\text { tsiinú-rixi }\end{array}$ & $\begin{array}{l}\text { conejo } \\
\text { cachorro }\end{array}$ \\
\hline$-\mathrm{T}$ & $\begin{array}{l}{ }^{2} \text { ukí } \\
\text { tepí }\end{array}$ & $\begin{array}{l}{ }^{2} \text { ukí-tsi } \\
\text { tepí-tsi }\end{array}$ & $\begin{array}{l}\text { varón } \\
\text { pulga }\end{array}$ & -TSIIXI & $\begin{array}{l}\text { 'irawe } \\
\text { kawayu }\end{array}$ & $\begin{array}{l}\text { Pirawe-tsixi } \\
\text { kawayu-tsixi }\end{array}$ & $\begin{array}{l}\text { lobo } \\
\text { caballo }\end{array}$ \\
\hline$-X I$ & $\begin{array}{l}\text { 'ukalái } \\
\text { teerika }\end{array}$ & $\begin{array}{l}\text { ?ukalái-xi } \\
\text { teriká-xi }\end{array}$ & $\begin{array}{l}\text { anciana } \\
\text { alacrán }\end{array}$ & -TEXI & $\begin{array}{l}\text { piitsi } \\
\text { mieme }\end{array}$ & $\begin{array}{l}\text { piitsi-texi } \\
\text { mieme-texi }\end{array}$ & $\begin{array}{l}\text { abeja de tierra } \\
\text { procedente }\end{array}$ \\
\hline$-\mathrm{M}$ & $\begin{array}{l}\text { ne-taru } \\
\text { ne-tewá }\end{array}$ & $\begin{array}{l}\text { ne-tarú-ma } \\
\text { ne-tewá-ma }\end{array}$ & $\begin{array}{l}\text { hermano } \\
\text { mis animales }\end{array}$ & -TERI & $\begin{array}{l}\text { kwitsi } \\
\text { piítsi }\end{array}$ & $\begin{array}{l}\text { kwitsi-teri } \\
\text { piitsi-teri }\end{array}$ & $\begin{array}{l}\text { gusano } \\
\text { rata de campo }\end{array}$ \\
\hline \multirow[t]{2}{*}{$-\mathrm{TE}$} & $\begin{array}{l}\text { kuche } \\
\text { muumé }\end{array}$ & $\begin{array}{l}\text { kuche-te } \\
\text { muumé-te }\end{array}$ & $\begin{array}{l}\text { mis coches } \\
\text { riñón }\end{array}$ & -MEXI & $\begin{array}{l}\text { tita } \\
\text { tixaiti }\end{array}$ & $\begin{array}{l}\text { tita-mexi } \\
\text { tixaiti-mexi }\end{array}$ & $\begin{array}{l}\text { quiénes } \\
\text { algunos }\end{array}$ \\
\hline & & & & -TERIX & $\begin{array}{l}\mathrm{ku} \\
\text { haiki }\end{array}$ & $\begin{array}{l}\text { ku-terixi } \\
\text { haiki-terixi }\end{array}$ & $\begin{array}{l}\text { serpiente } \\
\text { víboras azul }\end{array}$ \\
\hline
\end{tabular}

En otras lenguas como alemán, latín, griego o sánscrito los nombres forman también el plural con diferentes sufijos y otras marcas concomitantes como el umlau o apofonía.

\begin{tabular}{lllllll}
\multicolumn{2}{c}{ ALEMÁN } & & LATÍN & & \\
SG & PL & & SG & PL & \\
Tag & Tag-e & día & -e & littera & litterae carta & -ae
\end{tabular}




\begin{tabular}{|c|c|c|c|c|c|c|c|}
\hline Fuss & Füß-e & pié & $"-e$ & ager & agri & campo & $-\mathrm{i}$ \\
\hline Mädchen & n Mädchen & muchacha & $-\varnothing$ & dominus & domini & dueño & $-\mathrm{i}$ \\
\hline Mensch & Menschen & persona & -en & templum & templa & templo & $-\mathrm{a}$ \\
\hline Kind & Kinder & niño & -er & miles & milites & soldado & -es \\
\hline Haus & Häuser & casa & "-er & quercus & quercūs & encina & $-\mathrm{S}$ \\
\hline GRIEGO & & & & SÁNSCRITO & & & \\
\hline SG & PL & & & $\mathrm{SG}$ & PL & & \\
\hline heméra $\mathrm{h}$ & hemérai & día & $-\mathrm{i}$ & senā & senas & ejercito & -as \\
\hline oíkos & oíkoi & casa & $-\mathrm{i}$ & pasus & pasavas & ganado & -as \\
\hline patér & pátres & padre & -es & asvas & asvās & caballo & -ās \\
\hline lyon & lyontes & que desata & -es & madhu & madhuni & miel & $-\mathrm{i}$ \\
\hline rhódon 1 & rhóda & rosa & $-a$ & manas & manamsi & mente & $-\mathrm{i}$ \\
\hline hepar & hepata & hígado & $-a$ & & & & \\
\hline
\end{tabular}

Sin embargo, las diferencias son muy grandes por lo que vamos a distinguir entre clases nominales del wixárika y las clases flexivas de las lenguas indoeuropeas. Las clases flexivas resultan de un proceso de desemantización de clases nominales, que conduce finalmente a otra técnica de individuación llamada género/número. Los géneros conservan cierta transparencia semántica en la asignación de los nombres, aunque menor que en las clases; al menos en el dominio de los seres vivos se tiende a establecer una correspondencia entre los géneros y los sexos. La palabra varón es masculina, mujer es femenina. Existen, además, ciertas subregularidades como la correspondencia entre géneros y tamaño (charca - charco, barca - barco, canasta - canasto), o a significados como colectivo (la porra), regional (la Huasteca), institucional (la Radio - el radio).

En alemán, las palabras Pferd, Huhn, Rind y Schwein designan a las especies y son neutras (no especifican el sexo), mientras que Stute, Henne, Kuh y Sau son femeninas y designan a la hembra, Hengst, Hahn, Stier y Eber designan al macho, Fohlen, Küken, Kalb y Ferkel se refieren a las crías sexualmente inmaduras. A veces, la selección de la marca de plural está determinada conjuntamente por la terminación (auslaut, fonología) y el género: si una palabra termina en - $n d$ y es neutra, forma el plural con umlaut y el sufijo -er (Land / Länd-er "países"), pero si es masculina lo hace sin umlaut y con $-e$ : Land / Land- $e$ "regiones rurales". Lo mismo ocurre con Band / Bänd-er n. "lazo, banda, venda" frente a Band / Bänd$e$ m. "tomo, volumen" y Band-e "lazos afectivos"; Stand-Stände m., Sand/Sande m. "arenas" (sortal). En otros casos, un nombre neutro tiene un plural individuativo (Tuch / Tüch-er 
“trapo") y otro sortal (Tuch / Tuch-e "tipos de tejido"); Laus-Läuse, Maus-Mäuse son palabras femeninas, pero Haus-Häuser es neutra.

El género es en estos casos el factor determinante de la formación del plural y debe ser considerado como el factor dinámico del sistema gramatical de género/número. Todas las palabras tienen género, y del género depende que la alternancia de plurales tenga significado. Son los géneros los que podrían compararse con las clases nominales.

En las lenguas bantúes, las clases se expresan mediante la alternancia de dos marcas, una para el singular y otra para el plural; en algunos casos puede ser la misma (Serzisko, 1982).

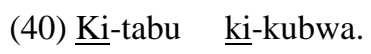

CL1-libro CL1-grande

"Un libro grande." (suahili)

(41) Ma-yai ma-dogo ni ma- bovu. (suahili)

CL6-huevo CL6-chico cípula CL6 podrido

"Los PEQUEÑos huevos están podridos"

En el primer ejemplo la marca de clase $k i$ - aparece no solamente en el nombre, sino también en el determinante atributivo que lo acompaña. En el segundo ejemplo ma- es la marca de la clase 6 en plural y aparece tanto en el atributo como en el predicado. La llamada concordancia es una característica muy conocida de los géneros:

(42) Un-o-s delicios-o-s huev-o-s rancher-o-s.

En suma, clases nominales, géneros y clases flexivas no son iguales, pero tampoco son absolutamente diferentes. Las diferencias y similitudes se pueden medir con distintos parámetros: amplitud del paradigma, carga y transparencia semántica, grado de variabilidad, concordancia, independencia de la fonología, pervasividad (si se extiende a todo el repertorio de nombres), prescindibilidad etc. 
Mientras los géneros suelen ser dos o tres, las clases nominales oscilan entre 4 y 12. Mientras los géneros y las clases nominales en otras lenguas se dan tanto en singular como en plural, las clases en wixárika y náhuatl se dan solamente en la formación del plural. Mientras los géneros y las clases nominales de otras lenguas sirven para expresar concordancia entre diferentes constituyentes sintácticos, en wixárika solamente aparecen en los nombres.

Si la comparación con los datos de las lenguas europeas y de otras familias es útil para descubrir tanto lo que es como lo que no es el sistema wixárika, lo que ocurre en esta lengua puede ayudar a la inversa a entender lo que pasa en las otras lenguas. La comparación nos proporciona una visión más amplia de la variedad de procedimientos con que las lenguas manejan el número gramatical, en qué tipo de oposiciones o distinciones se organiza, cómo se relaciona con otras categorías en las construcciones sintácticas, y nos puede revelar para qué necesitan las lenguas las clases nominales, las clases flexivas o los géneros. Diferencias y similitudes se subsumen en una relación de complementariedad, lo que permite ordenar estas técnicas en un continuo, dentro del cual podemos ubicar a las lenguas particulares:

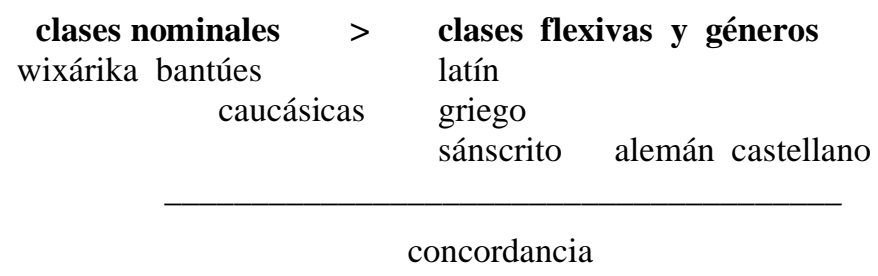

Esquema 2. Lenguas con clasificación nominal

En el esquema 2 presentamos la parte final de la escala de técnicas de INDIVIDUACIÓN que conllevan una clasificación de los nombres, ordenadas de izquierda a derecha empezando por las técnicas más predicativas. En la técnica de clases nominales, la clasificación se hace en base a la formación del plural. Wixárika y castellano ocupan las posiciones extremas de este segmento de la operación. En wixárika, los nombres que pertenecen a una misma clase comparten propiedades semánticas complejas. Hay bastante movilidad: un nombre puede formar el plural con varios morfemas de clase, con el consiguiente cambio de significado. En alemán, la clasificación en géneros se sistematiza en el singular; los géneros se neutralizan en plural, que es el locus de las clases flexivas. El castellano clasifica los nombres en dos 
géneros, masculino y femenino, tanto en singular como en plural, pero desaparecen las clases flexivas; es la lengua con el grado más alto de arbitrariedad o más bajo de semanticidad.

Un rasgo especial de variabilidad en el sistema de clases nominales en wixárika, nunca antes detectado ni siquiera previsto como posibilidad en la teoría relativa al número gramatical, es la pluralización reiterada o recursiva. Al plural normal se puede añadir otra marca de plural con un significado nuevo.

$\begin{array}{lll}\text { tuixu "cerdo" } & \text { tuixú-ri } & \text { tuixú-ri-ma "cerditos" (afectuoso) } \\ \text { 'ïrŕ "flecha" } & \text { 'ïrí-te } & \text { 'ïrí-te-xi "ancestros materializados en piedras de cuarzo" } \\ \text { tuutú "flor" } & \text { tuutúri } & \text { tuutú-ri-te "flores de diferentes tipos" } \\ \text { wakaxi "vaca" } & \text { wakái-tsiixi } & \text { wakái-tsiixi-te "figuras materiales de vacas" } \\ \text { ku "serpiente" } & \text { ku-terixi } & \text { ku-terixi-te "todo tipo de bichos" }\end{array}$

En el caso de tuixu se añade la marca de plural de los nombres de parentesco -ma para expresar cariño o proximidad afectiva, una estrecha cercanía al ego, como el diminutivo en otras lenguas En la medida en que solo se puede afijar a un nombre en plural, sigue siendo una marca de pluralidad: ne-tuixú-ri-ma '1POS-cerdo-PL-PL' "mis cerditos" (cerditos). Cuando 'ïrí designa la flecha como objeto material, forma el plural con -te, y la afijación adicional de la marca-xi ('ïrt́-te-xi) da a entender la reasignación al ámbito de lo sagrado; lo que se designa metafóricamente son pequeñas piedras de cuarzo consideradas como materializaciones de los antepasados. En tuutú-ri-te "flores de diferentes clases" y ku-terixite "bichos de todo tipo" el sufijo - te añade la idea de clase o tipo, es decir forma lo que se llama un plural sortal. En wakai-tsixi-te "figuras de vacas" -te da a entender que se trata de figuras o representaciones simbólicas y no de los animales vivos.

En ciertos tipos de composición, una marca de plural se afija al compuesto como tal, añadida a la marca que puede llevar cada uno de los nombres que forman parte del compuesto:

(43) [paapá tii-rí]-xi 'tortilla niño-PL-PL' 
Son pequeñas tortillas rituales. Como el compuesto constituye una nueva unidad léxica, es nuevamente pluralizado y asignado a una clase nominal diferente de la de los componentes del compuesto, donde - $x i$ expresa que se trata de un objeto perteneciente al ámbito simbólico o sagrado. Lo mismo ocurre en

(44) $[$ [ku-ku-terixi tei-terí]-xi]-yari “personas alimañas”
RED-serpiente:PL-PL persona:PL-PL-PL-COMP

A continuación vamos a exponer la riqueza semántica que puede portar una clase nominal. Los jóvenes que no han adquirido un conocimiento profundo de las costumbres y el simbolismo tradicional tienen dificultades para formar correctamente el plural de muchos nombres y tienen que hacer un esfuerzo adicional de memorización, similar o mayor a la que hay que hacer para memorizar el género de las palabras en castellano. El sistema de clases nominales no se sostiene sin el conocimiento de la cultura.

\section{La clase -RI}

El análisis contrastivo se puede utilizar como instrumento de desarrollo de teoría lingüística o como herramienta de desarrollo de la reflexión metalingüística sobre la materna. En el segundo caso, es necesario extender la contrastación al componente semántico frente al análisis distribucional que tiende a limitarse a los aspectos formales, tácticos, de combinación. Una comparación sobre las diferencias semánticas entre un sistema de clases nominales como el huichol y un sistema de géneros como el castellano puede contribuir enormemente a reforzar la competencia lingüística y a capacitar para el proceso de enseñanza-aprendizaje. Lo que sigue es una muestra del alto grado de semanticidad a que pueden llegar las clases nominales (Iturrioz et al. 1986a, 1986b), presentando de manera ejemplar una de ellas.

En wixárika observamos que las palabras pertenecientes al campo de los animales domésticos tienden a formar el plural con la misma marca: de tuixu "cerdo" se forma tuixú$r i$ "cerdos", de waakana "gallina" se forma waakana-ri "gallinas", de tst́ki "perro" se forma tsiiké-ri, de tsipu "chivo" tsiipúri. Hay animales domésticos, cuyos nombres forman el plural 
con el morfema-tsiixi: kapura-tsiixi "cabra", wakai-tsiixi "vaca", kawayu-tsiixi "caballo", mura-tsiixi "mula", puritu-tsiixi "burro", tsikeru-tsiixi "becerro". Estos nombres, tomados del español, designan especies traídas por los españoles e incorporadas tardíamente a la economía familiar de los wixáritaari. Por el contrario, dentro de la clase -ri tenemos la palabra tsipu, que viene de cast. chivo. Ciertas designaciones para las crías o cachorros no pertenecen a esta clase, aunque los nombres de la especie (tsiki y waakana) están en ella: tsiinú-rixi "cachorro de perro", pixixii-tsi "pollitos". Detrás de este diferenciado tratamiento de las palabras se hallan esquemas de percepción y conceptualización ligados a la manera de tratar y de interactuar con los referentes en la cultura wixárika: vacas, caballos, mulas, burros no nacen domesticados, sino que son domesticados o adaptados a la vida económica en el curso de su maduración mediante su explotación en labores que están a cargo de los varones. La vida de estos animales transcurre en buena parte fuera de la ranchería, en el campo abierto, mientras que en el caso de los primeros las mujeres asumen la tarea de cuidarlos. En el caso de los pollitos y de los cachorros, las personas no controlan todavía directamente su alimentación ni sus acciones, sino que es una relación mediada por los individuos adultos de esas especies. En el caso de los pollitos se indica adicionalmente que andan siempre en grupos numerosos o parvadas.

Nos acercamos un paso más a la comprensión de esta clase cuando observamos que también algunas designaciones personales pertenecen a ella, por ejemplo ’uká-ri "mujeres", tiit-rí (plural de nunutsi) "niños" y la misma palabra para el concepto de persona o gente tewi / teité-ri "personas". Las personas son naturalmente el centro de gravedad de la vida en la ranchería, pero de manera muy especial la mujer. La sociedad familiar tradicional wixárika es matrifocal, es decir tiene como centro o foco a la mujer. No solamente los niños, sino también los animales domésticos caen bajo su responsabilidad. La flor (tuutú-ri "flores") es el símbolo de la reproducción y todo el simbolismo relacionado con la reproducción, no solamente de la vida humana, sino también de la vida animal, del maíz etc. tiene como centro a la mujer.

Algunas palabras tomadas del español como munu "muñeco" y tsaatu "figuras de santos" forman el PL con la marca -ri, algo que podría resultar a primera vista extraño o, si se prefiere, una muestra de la arbitrariedad y autonomía de la lengua. Pero la extrañeza puede 
desaparecer si observamos finalmente que otras palabras como hutu, putu o chaxu forman el PL así; en ambos casos puede haber una asociación con lo femenino ya sea en el aspecto sexual o en lo llamativo de su apariencia. Los elementos de una clase nominal se ligan por asociaciones diversas con la representación compleja de la mujer. Y lo mismo vale para los santos, vestidos con ropajes llamativos, con rostros pintados etc.

Solo cuando se trata de nombres con referentes animados (o móviles) la marca de clase es obligatoria si se quiere hacer referencia a varios individuos; a su vez, el singular solo puede designar un referente. Con nombres de seres inanimados, la marca de plural no es obligatoria, el singular morfológico puede hacer referencia a una pluralidad, o simplemente es indiferente al número. Muchas veces la marca de clase designa un plural genérico o sortal (distintas clases del objeto en cuestión), como en paapá 'tortilla(s)' y paapá-te “tortillas (de diferentes tipos, en varios canastos)", o hace referencia a una pluralidad de medidas o recipientes:

(45) a. Paapá-te pi- ye- mane.

tortilla-PL PRIM-DENTRO- haber:PL

"Hay tortillas (en varios recipientes)."

b. Tuutúri-te ne- $\quad$ p- u- ti- nanai.

FLOR -PL 1SG.SUJ- PRIM-EXP-PL.A-compré

"Compré flores de varios tipos."

Con un sistema de clases nominales tan rico, formal y semánticamente, resulta sorprendente que el empleo de las marcas de plural es en gran medida facultativo. La opcionalidad de este sistema de marcas de clase se explica a su vez entre otras cosas por otra propiedad estructural del wixárika, tal vez la más destacable, o sea el carácter centralizante, consistente en acumular la mayor parte de la información en el predicado, generalmente verbal, a costa de las restantes clases de palabras.

\section{Conclusiones}

1. Categorías y estructuras son específicas de cada lengua, y por lo tanto no se pueden identificar plenamente con categorías y estructuras de otras lenguas sin incurrir en lo que Croft ha llamado en diversos trabajos oportunismo metodológico (Croft, 2001: cap. 1). 
2. Para hacer una comparación sin transferir propiedades de una lengua a otra, hay que empezar aplicando al output del análisis distribucional un análisis contrastivo, precisando en qué aspectos se parecen y en cuáles discrepan las categorías o estructuras respectivas.

3. De la evaluación de coincidencias y divergencias puede resultar una relación de complementariedad de la que inducimos un común denominador funcional. Podrían ser estrategias de una misma técnica, por ejemplo, formación de cláusulas determinativas, o varias técnicas con la misma función general, por ejemplo, géneros y clases nominales como técnicas de individuación.

4. La descripción de una estructura debe tener en cuenta la aportación de todos los elementos que la componen sin proyectar sobre ninguno de ellos características del contexto.

5. De una función compartida no se puede deducir una estructura común, dos estructuras diferentes pueden tener una función común, y una misma estructura puede expresar varias funciones.

6. El oportunismo metodológico se supera en la lingüística operacional (UNITYP) ordenando en cada nivel las categorías y las estructuras en continuos o escalas. La definición universal de $\mathrm{N}$ requiere construir como tertium comparationes un continuo de nominalidad. 


\begin{tabular}{|c|c|c|c|}
\hline \multicolumn{3}{|c|}{$\begin{array}{l}\text { Lista de abreviaturas } \\
\text { abs } \\
\text { absolutivo }\end{array}$} & \multirow{2}{*}{$\begin{array}{l}\text { nom nominalización } \\
\text { nominalizador }\end{array}$} \\
\hline as & asertor & nomr & \\
\hline aux1 & auxiliar1 (intransitivo) & & objeto \\
\hline aux2 & auxiliar2 (transitivo) & pas & pasado \\
\hline cisl & cislativo & $\mathrm{pf}$ & perfectivo \\
\hline comp & composición & & plural \\
\hline d1 & demostrativo 1 & & pluralidad de acción \\
\hline del & delimitativo & pos & posesión \\
\hline det & determinación & prim & primario \\
\hline erg & ergativo & & refl reflexivo \\
\hline $\exp$ & experiencial & rel & relativo \\
\hline fut & futuro & sec & modal secundario \\
\hline gen & generalización & sg & singular \\
\hline loc & localización & sub & subordinador \\
\hline neg & negación & suj & sujeto \\
\hline nexp & no experiencial & & \\
\hline
\end{tabular}

\section{Bibliografía}

Chafe, Wallace L. (1970): Meaning and The Structure of Language. Chicago/London: University of Chicago Press.

Coseriu, E. (1970): “Über die Leistung und Grenzen der kontrastiven Grammatik", en H. Moser (coord.): Probleme der kontrastiven Grammatik. Düsseldorf, pp. 9-30.

Croft, Williams (2001): Radical Construction Grammar: Syntactic Theory in Typological Perspective. Oxford University Press.

Dixon, R.M.W. (2010): Basic Linguistic Thery I-III. Oxford University Press.

Dryer, Matthew S. (1986): "Primary objects, secondary objects, and antidative", en: Language 62(4), pp. 808-845.

Dryer, Matthew S. (2008). "Descriptive theories, explanatory theories, and basic linguistic theory", en Felix K. Ameka et al. (eds.): Catching Language: The Standing Challenge of Grammar Writing. Berlin, New York: de Gruyter Mouton, pp. 207234.

Gómez López, Paula (2013): “Conectores intra e interoracionales en huichol: la pérdida de verbalidad y las propiedades del conector, dos parámetros relevantes”, en: Pérez, 
Bernardo (coord.): Procesos de cohesión textual. Estudios del huichol y del español. Morelia. Mich, pp. 15-34.

Grimes, J.E. 1964. Huichol Syntax. New York? De Gruyter Mouton.

Haspelmath, Martin (2010): "Framework-free grammatical theory", en: Heine, Bernd \& Narrog, Heiko (eds.): The Oxford handbook of grammatical analysis. Oxford: Oxford University Press, pp. 341-365.

Iturrioz Leza, José Luis (1985a): "La función de los afijos vascos -a/-ta a la luz de la dimensión de INDIVIDUACION”, en: Euskera 30, pp. 175-213.

Iturrioz Leza, José Luis (1985b): “Abstracción substantiva. Reificación de contenidos proposicionales”, en: Synbolae Ludovico Mitxelena Septuagenario oblatae, editado por José Luis Melena, pp. 396-414. Vitoria. Universidad del País Vasco.

Iturrioz Leza, José Luis (1986): "Structure, Meaning and Function. A Functional Analysis of Gender and Other Classificatory Techniques”, en: FUNCION I / 1, pp. 34-84.

Iturrioz Leza, José Luis (1987a): "Breve Historia de la Investigación en torno al Número Gramatical. III: La concepción operacional del número”, en: FUNCION II / 1, 120137.

Iturrioz Leza, José Luis (1987b): “Grammatical Number, Nominal Subcategorization, and Techniques for the Apprehension of Objects. II: The Operational Approach”, en: FUNCION II/1, pp. 12-53.

Iturrioz Leza, José Luis (2004): “Diversas aproximaciones a la nominalización: de las abstracciones a las macrooperaciones textuales", en: FUNCION 21-24, pp. 31-140.

Iturrioz Leza, José Luis (2014): “Características tipológicas fundamentales del huichol”, en: Dakin, Karen / José Luis Moctezuma (eds.): Lenguas Yutoaztecas: Acercamientos a su Diversidad Lingüística. México: UNAM, pp. 17-57.

Iturrioz Leza, José Luis (2021): "Plurifuncionalidad de -ME", en: Pérez Alvarez, Bernardo E. (coord.): Polifuncionalidad en lingüística. Morelia: UNAM. 
Iturrioz Leza, José Luis/ Gómez López, Paula (2006): Gramática Wixárika. München: LINCOM Europa.

Iturrioz Leza, José Luis/Paula Gómez López, Paula/Ramírez de la Cruz, Julio (1986a): "INDIVIDUACION en Huichol. I: "Morfología y semántica de las clases nominales", en FUNCION I/2, Universidad de Guadalajara, pp. 309-354.

Iturrioz Leza, José Luis / Paula Gómez López, Paula / Ramírez de la Cruz, Julio (1986b): INDIVIDUACION en huichol. II: "Aspectos morfológicos y sintácticos de las clases nominales", en: FUNCION I/3, Universidad de Guadalajara, 422-462.

Iturrioz Leza, José Luis / Ramírez de la Cruz, Xitakame (Julio) / Pacheco Salvador, Gabriel (2001): Gramática Didáctica del Huichol. Volumen I: Estructura fonológica y sistema de escritura, en FUNCION 19-20, Universidad de Guadalajara.

Iturrioz Leza, José Luis y Ana Line Martínez Sixto (2021): Las lenguas y los sentidos. Múnich: Lincom Europa.

Nebrija, Elio Antonio de (1492): Gramática castellana. Madrid.

Palafox Vargas, Miguel (1978): La llave del huichol. México: SEP-INAH.

Parra Gutiérrez, Rodrigo (2015): “El sistema de clases nominales del cora de Jesús María: motivación semántica y ubicación en el continuo de técnicas clasificatorias”, en: FUNCIÓN 35-36. De la Gramática a la Filosofía del Lenguaje. Universidad de Guadalajara, México.

Peirce, Charles Sanders (1931-1935): Collected Papers I-VI, editados por C. Hartshorne, P. Weiss \& A.W. Burks. Harvard University Press.

Piaget, Jean (1971a): “El desarrollo mental del niño", en: Seis estudios de psicología. Barcelona: Seix Barral, pp. 11-96. [versión original 1964]

Piaget, Piaget (1971b): "La epistemología genética", en: Psicología y Epistemología. Barcelona, Ariel, pp. 5-32. [versión original 1970]

Real Academia Española (1992): Diccionario de la Lengua Española. 21. edición. Madrid. Real Academia Española (2008): Corpus de Referencia del Español Actual. 
Real Academia Española (2009): Nueva gramática de la lengua española. Madrid: EspasaCalpe.

Serzisko, Fritz (1982a): “Gender, Nounclass, and Numeral Classification: A scale of classificatory techniques”, en: Dirven, R. y Radden, G. (eds): Issues in the Theory of Universal Grammar (TBL 196). Tübingen: Gunter Narr Verlag.

Tapia Zenteno, Carlos de (1753) Arte novíssima de lengua mexicana. México: Viuda de D. Joseph Bernardo de Hogal. 